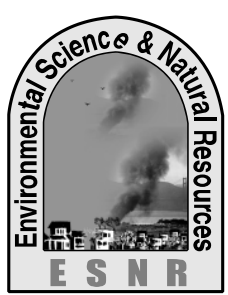

\title{
Water Supply and Sanitation Status of Haryzon Polly Dwellers at Natunbazar Area in Mymensingh District
}

\author{
S. Rana, H. K. Ghosh, M. A. Sattar and M. A. Ali* \\ Department of Environmental Science, \\ Bangladesh Agricultural University, Mymensingh-2202, Bangladesh \\ *Corresponding author: litonaslam@yahoo.com
}

\begin{abstract}
Information was collected from various respondents through survey using prescribed questionnaire in Haryzon Polly area at Natun Bazar located under Sadar Upazila in Mymensingh district. It was found that about 56\% people were dependent on deep tube-well water for their daily household purpose. The remaining $44 \%$ was dependent on tap water supply. According to the respondents, deep tube wells water were mostly used (98\%) for drinking purpose and remaining $2 \%$ was used by tap water. Of them supply water was used in toilet purpose by $71 \%$ and deep tube-well water by $29 \%$. Most of the people of Haryzon Polly at Natunbazar in Mymensingh district were conscious regarding sanitation, but a large portion of them were unaware of safe hygiene. The people dump children feces $60 \%$ in open places. Seventeen percentage children did not have any proper knowledge about sanitation. Most of the people have no proper training about sanitation. The survey also indicated that the overall hygienic condition of the respondents and sanitation condition of study area were poor in Haryzon Polly area at Natun Bazar, where both sanitary and hygiene condition were found to be acceptable condition.
\end{abstract}

Key words: Haryzon polly, Hygiene, Sanitation, Water supply

\section{Introduction}

Health problems related to the inadequacy of water supplies are universal but generally of greater magnitude and significance in developing countries. Although population under water supply coverage improved significantly during the Water Supply and Sanitation decade and after the decade, it has been estimated about that $25 \%$ of the population in developing countries still does not have access to safe water (WHO, 2000). As a result, millions of people in developing countries suffer from water-related diseases each year. The infant mortality rate is still very high in developing countries largely due to lack of safe water supply and sanitation and unhygienic condition (Ahmed and Rahman, 2000). In Bangladesh, every year almost 3 million children under five years of age die of diarrheal disease and every child suffers and average of three times diarrheal attacks in a year (UNICEF, 2000) It is recommended that diarrheal diseases can be prevented easily with the use of safe water and hygienic sanitation (WHO, 2000). According to Mathew (2003), lack of sanitation and poor hygiene are responsible for the transmission of diarrhea, cholera, typhoid and several parasitic infections. Moreover, the incidence of these diseases and others linked to poor sanitation e.g., round worm, whip worm, guinea worm, and schistosomiasis is highest among the poor, especially school-aged children. These diseases have a strong negative impact on the health and nutrition of children and their learning capacities, and contribute to significant absences from school. More than 2.2 million people in developing countries, most of them children, die each year from diseases associated with lack of access to safe drinking water, inadequate sanitation and poor hygiene.

According to Mymensingh Pourashava (2013) the poor, and in particular the slum dwellers suffer from insufficient basic infrastructure services, namely insufficient and unhygienic sanitation. In most slum areas a few pit latrines have to be shared by a large number of households (for instance, in the towns' sweeper colony, more than 1000 inhabitants have to share only toilets). Generally, almost one third of slum household uses kutacha toilets or open holes. Insufficient sanitation is compounded by frequent flooding, resulting in seriously unhygienic conditions in which human excreta often find their way into drainage canals and water bodies. Water is usually provided through tube well hand pumps, against shared by large number of households. Also, water quality is generally worse in slum area, with a higher share of unclean and contaminated water. According to DPHE (2007), in recent past, $97 \%$ of the people had access to safe water within 150 meters. With the discovery of arsenic in groundwater, the coverage has come down to about $75 \%$. However, alternative options are being implemented for supply of arsenic safe water. 


\section{Materials and Methods}

\section{Location and studied areas}

Haryzon Polly at Natun Bazar is located under Mymensingh Sadar Upazila in Mymensingh District and Ward No.10. It is bordered and surrounded on the north by Rail line road, on the south by Naumahal road, on the east by the Mazar Sharif road and on the west by Ganginar par road. About 850 dwellers live here and most of the people lives below poverty line. They are much more lag-behind than other areas because of poverty, unemployment, low literacy and lacking of awareness about their self-condition. Haryzon Polly area is a slum area. Their main occupations are sweeping, cleaning of streets, drains and toilets and their average income was 5000 taka. They live from hand to mouth. (Source: Mymensingh Poutashava, 2013). Data was collected from the primary and secondary sources which have been assembled in tabular form.

\section{Results and Discussion}

\section{Male and female respondents}

Fig.1 showed that respondents of the study area which were grouped into male and female. It was observed that $63 \%$ respondents were male and $37 \%$ respondents were female. Although female were involved in managing water supply and sanitation sector but male respondents were more interested in interview.

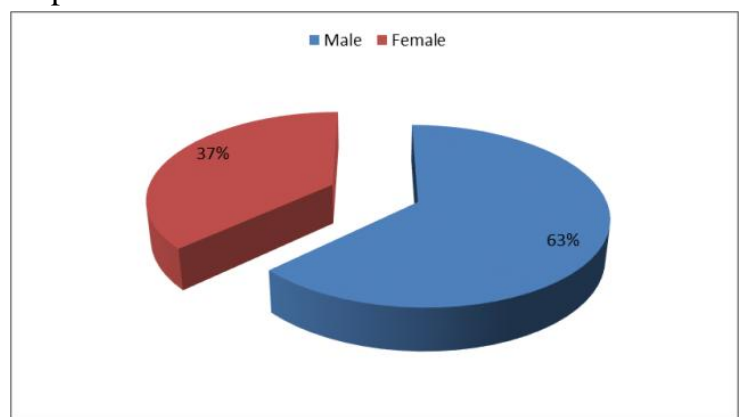

Fig. 1. Male and female of the respondents

\section{Age distribution of the respondents}

From the questionnaire interviewed it was found that Respondent were categorized into four group fig. 2 showed that maximum $46 \%$ of the total population were found between 31 to 40 years. About $39 \%$ populations were found between 15 to 30 year's age and $10 \%$ people were between 41 to 50 years. Other $5 \%$ of population was above 50 years. Among the respondent groups it was found that between 15 to 30 year's aged people were most conscious about sanitation due to participating different training programs.

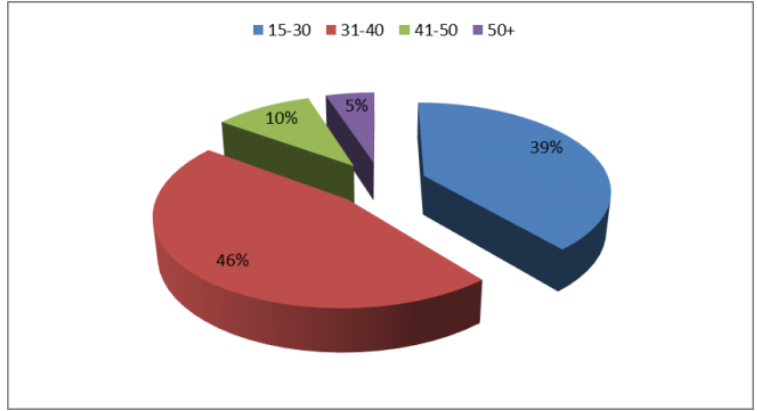

Fig. 2. Age distribution of the respondents

Available sources of water

Fig. 3 showed that the available source of water of the study area where the source of water were grouped in deep tube-well and supply water. Among them the usages of deep tube-well water $56 \%$ and pipe line supply water system $44 \%$. Rain water is not used necessarily though it is most available in the rainy season only. The findings indicated that deep tube well water was most available source for household purposes in the study area.

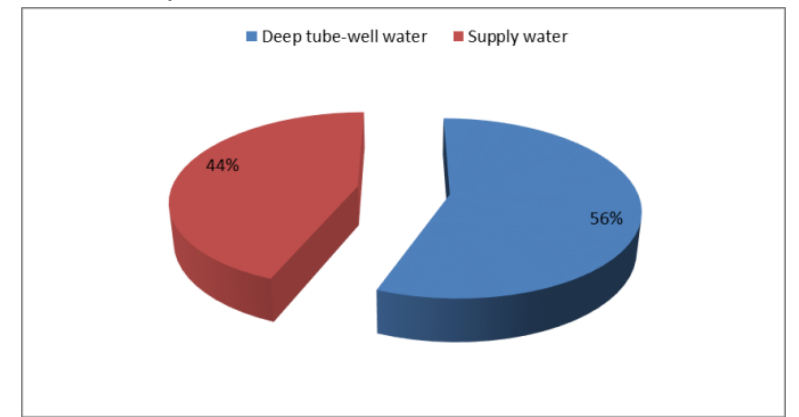

Fig. 3. Available source of water in the study area.

\section{Sources of water for drinking purpose}

In drinking purposes, Fig. 4 showed that most of the people use the deep tube-well. Among the respondents the deep tube-well water users were $98 \%$ and supply water $2 \%$. Deep tube-well water indicated the Arsenic free tube-well water which was funded by the government and a few was funded by individual. The usages of supply water were negligible in drinking purpose.

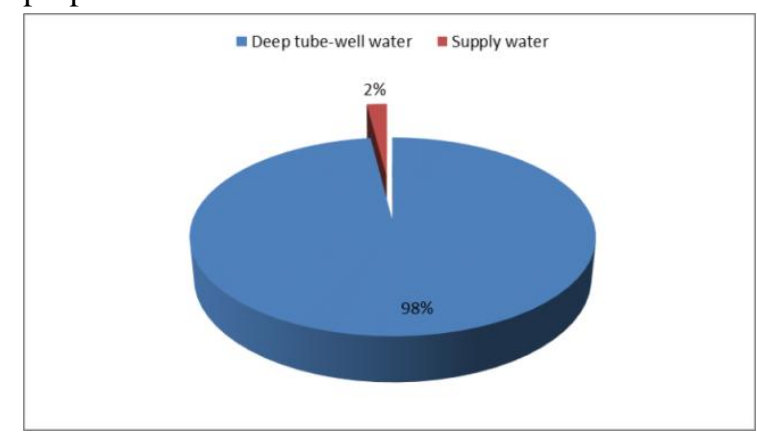

Fig. 4. Sources of water for drinking purpose 


\section{Sources of water for toilet purpose}

In toilet purpose the usages of supply water was the most and it was $71 \%$. Twenty nine percentages deeptubewell water was used in toilet purpose. Fig.5 showed that the details about the usages of water in toilet purpose.

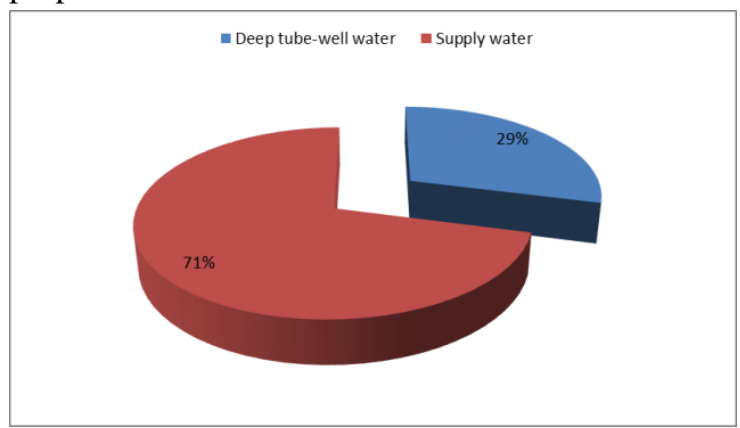

Fig. 5. Sources of water for toilet purpose

\section{Hygiene awareness development among children}

Fig. 6 represents the training of children about hygienic condition which were grouped into- trained up and not trained up. It showed that $83 \%$ respondents trained up their children about hygienic condition. The rest of $17 \%$ respondents never trained up their children about hygienic condition. Thus from the findings it was found that most of the children were trained up by their parents or senior family members which was a good sign for the safe hygiene of a locality. But a larger numbers of children were not trained up and it cause a severe problem in case of safe hygiene.

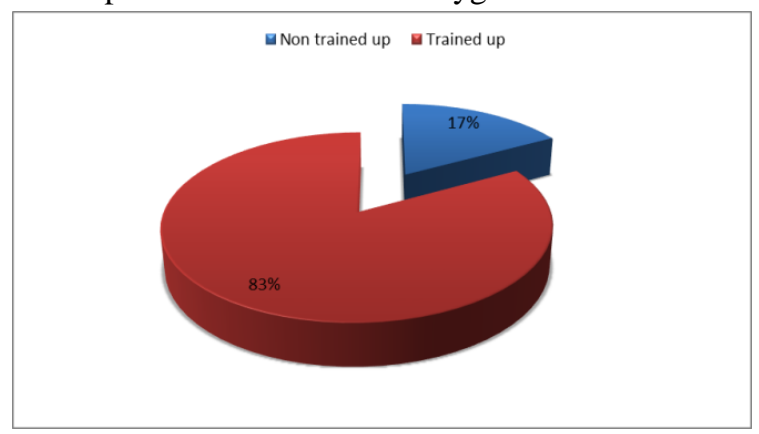

Fig. 6. Training of children about hygienic condition

\section{Management of children feces}

Fig. 7 represents the management scenario of children feces in the study area. It was showed that in case of $60 \%$ children, feces were dumped into sanitary latrine. But about $40 \%$ children, feces were dumped into open places. In the study area there was no use of small latrine. The findings indicated that feces of the most numbers of children were dumped into latrine. This type of management was good for the safe hygiene issue.

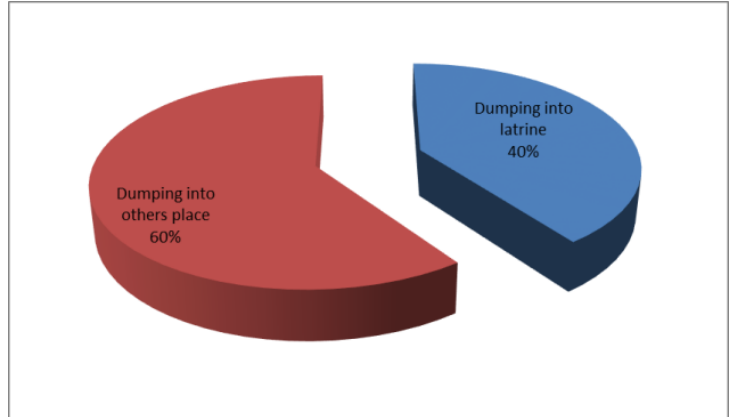

Fig. 7. Management of children feces

Role of local government and NGOs on sanitations condition

Fig.8 represents the role of local government and NGOs in improving sanitation status according to the respondents. It showed that about $92 \%$ respondents said that pourashava was not involved in improving sanitation status in the study area. Only about 1\% respondents said that pourashava is involved in improving sanitation status. Others $7 \%$ was showed their acknowledgement on the NGO. Thus, it was found that pourashava was not so much involved in improving sanitation condition in the locality.

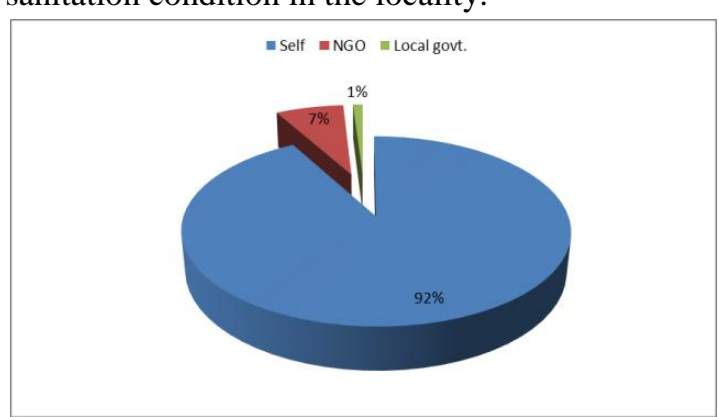

Fig. 8. Role of Local government and NGOs

\section{Conclusions}

According to Mymensingh pourashava, every household was a sanitary latrine. The main two types of sanitary latrines were used in that area, ring slab latrines $86 \%$ and ventilated improved pit latrine $14 \%$. Of them NGOs $7 \%$ and local government $1 \%$ gave the ring slab latrines among the poor people. Ring slab latrines was used for low cost of it installation and maintenance. The people cleaned their sanitary latrines with deep-tubewell water in the interval of 6-8 days. Local government like the pourashava is not actively involved in sanitation status of the study area. On the contrary, NGOs have taken some responsibilities and helped the people in installation of sanitary latrines, arranged awareness building program, etc. Mymensingh pourashava is announced as $100 \%$ sanitation coverage but only $1 \%$ established, though there are some major threats against it. Children feces one of the major threats for sanitation as $60 \%$ children feces were 
dumped into other places without any covering. Another major threat was that $96 \%$ sanitary latrine is cleaned by only water. The sanitation condition of Haryzon Polly at Natunbazar area in Mymensingh district is more or less same for all the other rural area of Bangladesh. Through awareness building about the safe and hygienic living can be an effective tool to battle against the unsafe and diseases of human health in future.

\section{References}

Ahmed, F. and Rahman, M. M. 2000. Water Supply and Sanitation: Rural and Low Income Urban Communities, ITN-Bangladesh, Dhaka, 100p.
Department of Public Health Engineering (DPHE). 2007: DPHE Overview. Department of Public Health Engineering. Dhaka, Bangladesh.

Mathew, K. 2003. Worms: Identifying Impacts on Education and Health in the Presence of Treatment Externalities. February, 2003. Department of Economics, Harvard University.

Mymensingh Pourashava and Mymensingh Pourashava Office, 2013. Kutachari Road, Mymensingh.

UNICEF. 2000. Global Water Supply and Sanitation Assessment, A midterm assessment of progress, UNICEF, Geneva, Switzerland, New York, USA.

WHO. 2000. Guidelines for Drinking-Water Quality, 1, Recommendations, $3^{\text {rd }}$ edition, Geneva. ISBN 9251546387. 